\title{
LCLE - Localizador Coletor de Lixo Eletrônico
}

\author{
Alex R. M.C. Wanderley ${ }^{1}$, Juliano Ratuznei ${ }^{2}$, Wellington da Silva ${ }^{3}$ \\ ${ }^{1}$ Mestrando em Ciências da Computação - Faculdade Campo Limpo Paulista \\ (FACCAMP) \\ Rua Guatemala, 167 - 13231-230 - Campo Limpo Paulista - SP - Brasil \\ ${ }^{2}$ Mestre em Engenharia da Informação - Universidade Federal do ABC (UFABC) \\ Av. dos Estados, 5001 - 09210-580 - Santo André - SP - Brasil \\ ${ }^{3}$ Mestrando em Educação - Universidade Cidade de São Paulo (UNICID) \\ Rua Cesário Galeno, 448/475 - 03071-000 - São Paulo - SP - Brasil \\ alexwanderley_analista@hotmail.com, juliano.r@ufabc.edu.br, \\ prof.wellingtonsilva@gmail.com
}

Abstract. This meta-article presents a prototype of a mobile application called LCLE - Garbage Collector Locator, which uses geolocation to inform the application users the nearest point of the specific garbage collector; According to the United Nations, Brazil is the emerging country that most produces the electronic waste, more than 1 million tons per year, perhaps only a two percent is recycled in this country; In view of the study the LCLE Electronic Garbage Collector Locator is project and based on the UN data, which it is a collaborative solution for developed economically and technically, with the general objective is of disseminating the practice of the correct disposal of electronic waste through an application for cell phone.

Resumo. Este meta-artigo apresenta um protótipo de aplicativo para celular chamado LCLE - Localizador Coletor de Lixo Eletrônico, que utiliza a geolocalização para informar ao usuário do aplicativo qual é o ponto de coleta de lixo eletrônico mais próximo dele; Segundo a Organização das Nações Unidas (ONU), o Brasil é o país emergente que mais produz lixo eletrônico, são mais de 1 milhão de toneladas por ano, dos quais, somente um percentual de 2\% é reciclado; Diante do estudo do projeto LCLE Localizador Coletor de Lixo Eletrônico e com base nos dados da ONU, desenvolveu-se uma solução colaborativa viável técnica e economicamente, com o objetivo geral de disseminar a prática do descarte correto do lixo eletrônico através de um aplicativo para celular. 


\section{Introdução}

De acordo com relatórios da ONU - Organização das Nações Unidas de 2012, o lixo eletrônico crescerá aproximadamente no percentual de 33\% em todo o mundo até 2017 , correspondendo a 65,4 milhões de toneladas. Nestes produtos são encontradas diversas substâncias que podem causar sérios danos ao meio ambiente e a saúde humana. As baterias de celular são um bom exemplo, pois muitas delas levam a mistura níquelcádmio, constituindo uma combinação altamente tóxica que pode causar câncer em diversos órgãos do corpo humano, ataques asmáticos e outros problemas de pulmão, fígado e sangue. Ainda segundo a Organização das Nações Unidas (ONU), o Brasil é o pais emergente que mais produz lixo eletrônico, são mais de 1 milhão de toneladas por ano, dos quais, somente um percentual de $2 \%$ é reciclado.

Segundo Costa. et. al., a consciência ambiental deve ser tema desde as escolas infantis até as pós-graduações a principal gravidade do problema é que muitos adultos acreditam que só o computador dele irá para o lixo. É preciso conscientizar e investir em campanhas para divulgar de forma correta o descarte do lixo eletrônico e, além disso, que as cidades mantenham pontos de recebimento em diferentes regiões da mesma para facilitar que as pessoas entreguem esse lixo, ficando a cargo de entidades apropriadas reaproveitar ou encaminhar pra reciclagem.

Diante desta preocupação com o meio ambiente, visto que o curso de informática possibilita a criação de sistema e aplicativos, e segundo Veiga (2001) enfatiza que a informática adotada nas escolas integra o ambienta escolar a realidade dos alunos, não só como ferramenta mas também como recurso interdisciplinar que os docentes possam contar para bem realizar o seu trabalho, desenvolvendo atividades, projetos e questionamentos com os alunos.

Tendo em vista o problema apresentado e os conceitos citados desenvolveu-se um protótipo de um aplicativo para celular que utiliza a geolocalização para informar ao usuário do aplicativo qual o ponto de coleta de lixo eletrônico mais próximo dele. $\mathrm{O}$ diferencial do LCLE é que o usuário poderá selecionar a distância para a realização da pesquisa e fazer o cadastro de pontos de coleta, sendo uma ferramenta colaborativa e de preocupação ambiental.

Além disso, compreendeu-se que existem poucos pontos de coleta de lixo eletrônico principalmente na região leste de São Paulo, dificultando a entrega pelos usuários e empresas, tendo o lixo comum recebido diversos materiais que poderiam ser reutilizados, reciclados ou seguindo o destino correto de descarte.

O aplicativo de celular tem a finalidade de realizar cadastro e localização de pontos de coleta de lixo eletrônico para facilitar a busca de locais adequados para o descarte do lixo eletrônico na região, proporcionando o descarte correto e o desenvolvimento da cultura da colaboração e da sustentabilidade.

Esse trabalho está dividido em cinco seções, sendo a primeira a introdução, a segunda metodologia, a terceira seção faz uma apresentação do protótipo, descrevendo as suas funcionalidades e características, a quarta seção apresenta os resultados de discussão finalizando a quinta seção com Conclusão e Trabalhos Futuros. 


\section{Metodologia}

Utilizou-se pesquisa aplicada com o embasamento teórico para o contato com as normas e com banco de dados de resumos e artigos, bem como, leitura de jornais e revistas acadêmicas, literaturas e bibliografias das áreas estudadas, tendo como área de aplicação o Meio Ambiente e área de Pesquisa Engenharia de Software, objetivando o fortalecimento da educação ambiental na escola, no entorno e no Brasil, especificamente no descarte de lixo eletrônico;

$\mathrm{O}$ guia de gerenciamento de projetos $\mathrm{PMBOK} 5^{\circ}$ Edição foi utilizado como referência para a estruturação deste projeto, auxiliando no desenvolvimento do protótipo;

A ferramenta utilizada para desenvolver o aplicativo foi o Android Studio da empresa Google, a base de dados utilizada foi o SQL Lite, o aplicativo MSProject da empresa Microsoft foi utilizado para realizar o planejamento e cumprimento do cronograma de desenvolvimento do protótipo e para a modelagem do aplicativo foram utilizados diagramas UML.

Uma forma de validação do protótipo LCLE foi ele ser selecionado para participar da $15^{\mathrm{a}}$ edição da FEBRACE - Feira Brasileira de Ciências e Engenharia, organizado pela Escola Politécnica da USP, onde foi apresentando a diversos visitantes que fizeram muitos elogios e sugestões ao protótipo, ele também recebeu o Prêmio Programaê! de Invenção e Criatividade.

\section{Apresentação do Protótipo}

Nesta seção serão apresentadas das telas e funcionalidade do aplicativo.

\section{1. Ícone de identificação do protótipo LCLE}

O protótipo LCLE será identificado nas lojas de aplicativos pela figura 1 .

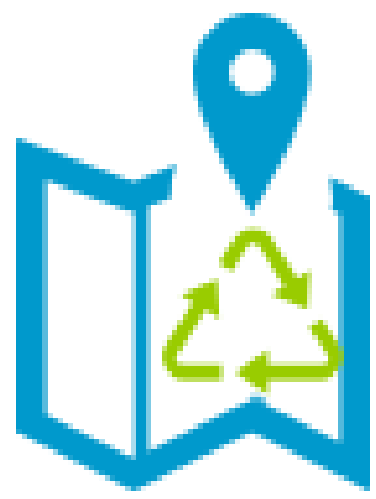

Figura 1. Ícone do protótipo LCLE 
VI Congresso Brasileiro de Informática na Educação (CBIE 2017)

Anais do XXIII Workshop de Informática na Escola (WIE 2017)

\subsection{Tela Inicial do Protótipo LCLE}

A tela inicial do aplicativo é apresentada na figura 2, Protótipo de LCLE, na qual basta o usuário selecionar o item a ser descartado, selecionar a distância desejada para localizar um coletor de lixo eletrônico (no exemplo a distância foi de $3 \mathrm{KM}$ ) e clicar no botão pesquisar, o resultado da consulta será apresentado na figura 3.

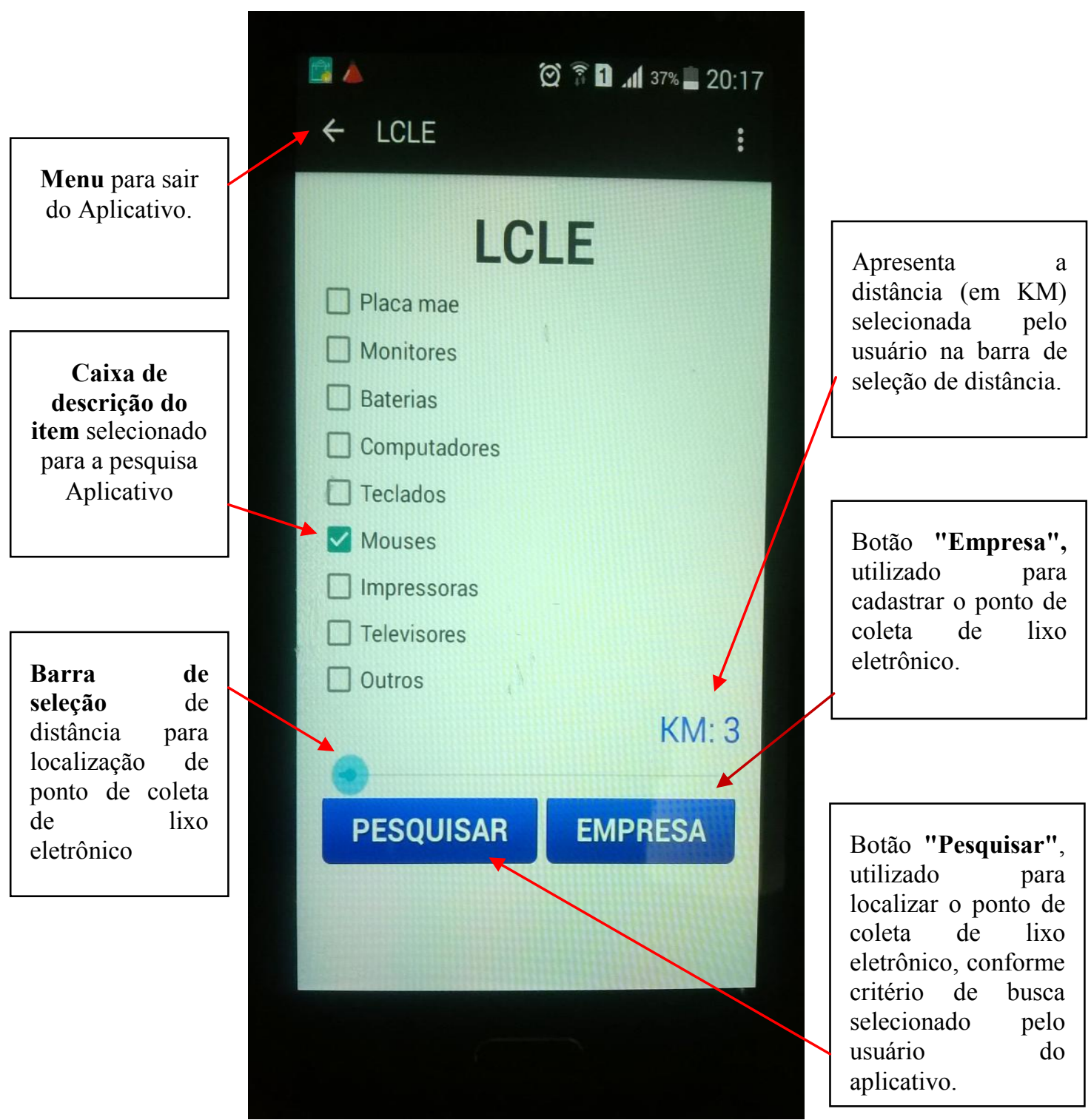

Figura 2. Tela inicial do protótipo LCLE

Utilizou-se no aplicativo de poucos controles para o usuário selecionar visando a prática da usabilidade e focando na utilidade principal do aplicativo. A ferramenta desenvolvida deve ajudar é não ser mais um fator de dificuldade encontrada pelo usuário à encontrar um local apropriado para o descarte do lixo eletrônico. 
VI Congresso Brasileiro de Informática na Educação (CBIE 2017)

Anais do XXIII Workshop de Informática na Escola (WIE 2017)

\subsection{Tela de localização dos pontos de coleta}

Na tela de localização dos pontos de coletas (figura 3) um mapa indicando os pontos onde foram localizados pontos de coleta de lixo eletrônico será apresentado ao usuário do aplicativo, que deverá clicar sobre os pontos localizados para que sejam apresentados os nomes das empresas, em negrito, endereço, sítio na internet e email, se houver, e telefone, conforme indicado na seta abaixo.

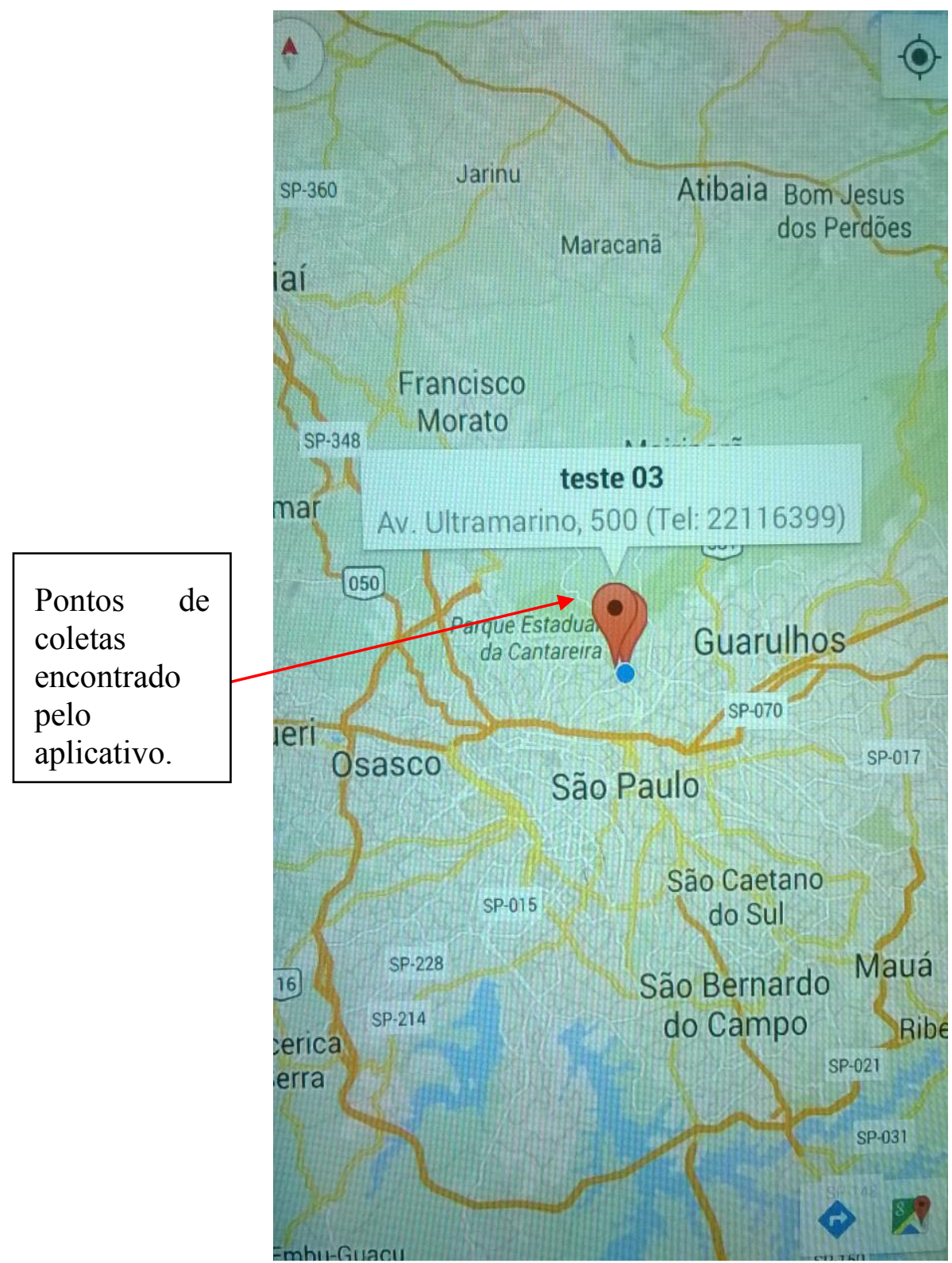

Figura 3 - Tela de resposta da pesquisa do protótipo LCLE, com indicação do endereço e telefone do ponto de coleta. 
VI Congresso Brasileiro de Informática na Educação (CBIE 2017)

Anais do XXIII Workshop de Informática na Escola (WIE 2017)

\subsection{Tela de cadastro dos pontos de coleta}

No botão "EMPRESA", localizado na figura 4, será possível realizar o cadastro dos pontos de coleta de lixo eletrônico, ao clicar no citado botão "EMPRESA", aparecerá a figura 4, qualquer pessoa cadastrada no sistema poderá realizar o cadastro no aplicativo.

Sugere-se ao usuário realizar no mínimo o cadastro de três pontos de coletores de lixo eletrônico para realização do teste de geolocalização.

\section{LCLE}

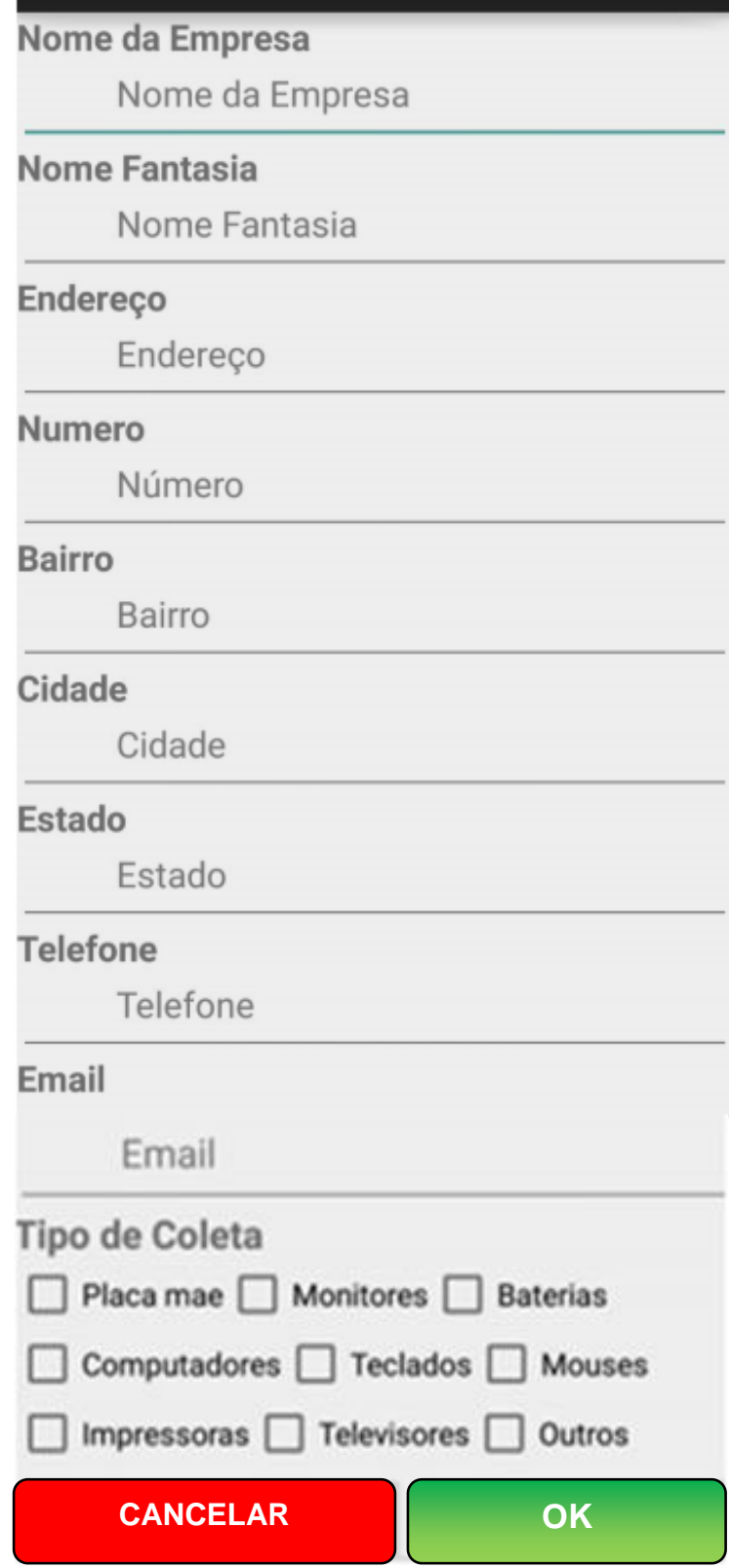

Figura 4 - Tela de cadastro de empresa, do protótipo LCLE. 


\section{Resultados de Discussão}

Alcançou-se a construção de um aplicativo com a utilização de ferramentas tecnológicas que proporcionam uma visão educacional sobre o uso das tecnologias e sua relação com o meio ambiente.

No aspecto discente foram formadas equipes, as quais ficaram entusiasmadas em atuar com o projeto do Aplicativo Localizador Coletor de Lixo Eletrônico, desta forma, espera-se dar um enfoque em usabilidade e continuar a estruturação do projeto e o envolvimento com as disciplinas técnicas, como programação, lógica e desenvolvimento, realizando um contato próximo entre teoria e prática.

Percebeu-se que após a divulgação na mídia do projeto, dos alunos e da comunidade escolar, a comunidade ficou mais interessada em participar das atividades escolares, pois a escola ultrapassou as barreiras da atividade acadêmica clássica passando a atuar no ramo de projetos, motivando e beneficiando a sociedade.

Os envolvidos neste projeto foram alunos de nível médio técnico, os quais possuem falta de incentivo, suporte e carência de projetos, estes alunos possuem imenso potencial, porém é necessário ocorrer comprometimento por parte da gestão e docentes para fomentar o desenvolvimento deste potencial. O suporte deve ocorrer antes, durante e depois do desenvolvimento do projeto, e não ocorrer, somente quando já há visibilidade.

O aplicativo desenvolvido necessita de ser disponibilizado aos usuários, então a equipe atual fará os estudos necessários tanto de divulgação como de cadastros de novos pontos de coleta e a criação de novas ferramentas e ideias.

Os estudos demonstraram resultados nos aspectos de motivação dos alunos e aprendizagem baseada em projetos, contribuindo para a visibilidade do professor tornando-o autor, pesquisador e grande influenciador na sala de aula para as novas aprendizagens.

\section{Conclusão e Trabalhos Futuros}

O pressuposto trabalho realizado já gerou de resultado para a comunidade cientifica um aplicativo importante e relevante para o exercício da relação cidadão e meio ambiente. Os objetivos foram alcançados, mas pretende-se continuar os estudos para disponibilizar o aplicativo e ter os usuários utilizando para ter a massa crítica e retornos sobre a interface e as demais tecnologias empregadas. (FEBRACE 15).

O projeto apresenta-se como relevante e de suma importância para a busca do direcionamento do lixo eletrônico, bem como, de disseminação da cultura de colaboração, reciclagem e parceria entre entidades, cidadãos, escolas e universidades.

Com a estruturação da hipótese, um aplicativo de celular para cadastro e localização de pontos de coleta de lixo eletrônico pode facilitar a busca de locais adequados para o descarte do lixo eletrônico na região, proporcionando o descarte correto e o desenvolvimento da cultura da colaboração e da sustentabilidade, entende-se 
VI Congresso Brasileiro de Informática na Educação (CBIE 2017)

Anais do XXIII Workshop de Informática na Escola (WIE 2017)

que o aplicativo proporciona estes princípios elaborados, mas constata-se a necessidade de disponibilizar, melhorar o protótipo e incluir as pessoas com deficiência neste processo.

Para dar continuidade às próximas atividades são de inserção do banco de dados para o aplicativo, em seguida sua disponibilização em Playstore, posteriormente divulgar e analisar os resultados dos usuários. Como outra etapa do projeto estuda-se incluir a utilização para pessoas com deficiência e melhorar a interface conforme a dinâmica do uso.

\section{Referências}

Costa. et al.; Avaliação do Destino do Lixo Eletrônico do Município de Inhumas. Anais do XXII SBIE - XVII WIE, Aracaju, novembro de 2011. Disponível em: $<$ http://www.br-ie.org/pub/index.php/wie/article/view/2021/1780>, acessado em 26 de maio de 2017.

Febrace, Feira Brasileira de Ciências e Engenharia. Disponível em: $<$ http://febrace.org.br/>, acessado em 03 de maio de 2017.

Febrace 15 (2017) "Criatividade e Inovação: LCLE - Localizador Coletor de Lixo Eletrônico”, ISBN 978-85-86686-93-1, São Paulo, SP, Anais 2017, p 45.

Kamienski, Carlos et al. Application development for the Internet of Things: A contextaware mixed criticality systems development platform. Computer Communications, v. 104, p. 1-16, 2017.

Lecheta, Ricardo R.(2015) “Google Android”. Novatec, p 1072.

Macauley, M.; Palmer, K.; Shih, J.; Dealing with electronic waste: modeling the costs and environmental benefits of computer monitor disposal. Journal of Environmental Management, v. 68, n. 1, p. 13-22, 2003

Mcalister, A.; Horan, E.; Acceleration of E-Learning in Australia and Impacts of EWaste: Approaches to Reforming E-Learning in the 21st Century. In: Conference Proceedings. The Future of Education. libreriauniversitaria. it Edizioni, 2017. p. 63.

Miguez, E. C. (2010).; "Logística reversa como solução para o problema do lixo eletrônico: benefícios ambientais e financeiros”. Rio de Janeiro: Qualitymark, p 99.

Petridis, N. E. et al. Estimation of computer waste quantities using forecasting techniques. Journal of Cleaner Production, v. 112, p. 3072-3085, 2016.

Project Management Institute (2013). "Um guia do conhecimento em gerenciamento de projetos: guia PMBOK. 5. Ed”. Pennsylvania: Project Management Institute, p 589.

PWC PriceWaterhouseCoopers Serviços Profissionais Ltda. Guia de Orientação para Adequação dos Municípios à Política Nacional de Resíduos Sólidos (PNRS). São Paulo, 2011. 
VI Congresso Brasileiro de Informática na Educação (CBIE 2017)

Anais do XXIII Workshop de Informática na Escola (WIE 2017)

Oliveira. A. M., Ludwig. L., Finco, M.D.; Proposta Pedagógica do Uso das TICs como Recurso Interdisciplinar. Anais do XXII SBIE, Aracaju, novembro de 2011. Disponível em: <http:/www.br-ie.org/pub/index.php/wie/article/view/1974/1733>, acessado em 26 de maio de 2017.

de Oliveira, et al.; Logística reversa: uma análise do descarte de baterias e celulares nos pontos de coleta da Claro em Chapecó -SC. Amazônia, Organizações e Sustentabilidade . Ago-dez 2013, Vol. 2 Issue 2, p79-95. 17p.

Organização das Nações Unidas - ONU. Relatório prevê que mundo terá 50 milhões de toneladas de lixo eletrônico em 2017, Disponível em: $<$ https://nacoesunidas.org/onupreve-que-mundo-tera-50-milhoes-de-toneladas-de-lixo-eletronico-em-2017/>, acessado em 30 de novembro de 2016.

Robinson, B. H.; E-waste: an assessment of global production and environmental impacts. Science of the total environment, v. 408, n. 2, p. 183-191, 2009.

Vazquez, Y. V.; Barbosa, S. E. (2016).; Recycling of mixed plastic waste from electrical and electronic equipment. Added value by compatibilization. Waste Management, 53, 196-203.

Wang, Haoyu et al. An Explorative Study of the Mobile App Ecosystem from App Developers' Perspective. In: Proceedings of the 26th International Conference on World Wide Web. International World Wide Web Conferences Steering Committee, 2017. p. 163-172. 